\title{
Different methods of treatment of liquid systems and solutions: a review
}

\section{Iryna Dubovkina}

\section{Institute of Engineering Thermophysics of National Academy of Sciences of Ukraine, Kyiv, Ukraine}

\section{Keywords:}

Water

Liquid

Hydrated

Treatment

Pressure

\section{Article history:}

Received 21.07.2019

Received in revised

form 18.10.2019

Accepted 28.11.2019

\section{Corresponding author:}

Iryna Dubovkina

E-mail:

dubovkinai@ukr.net

DOI: $10.24263 / 2310-$

1008-2019-7-2-14

\section{Abstract}

Introduction. The purpose of this reseach is to investigate different methods of the treatment of the liquid systems and solutions for the change of the chemical and physical parameters and properties these liquid systems and solutions.

Materials and methods. Objects of research are different types of treatment and processing methods end modes of liquid water systems and solutions like as technological water for the application in food industry. Subjects of study are change of the physical and chemical parameters and properties of water systems and solutions. Scientific and research works, reviews, articles, monographs of different methods and processes of treatment water systems were analyzed.

Results and discussion. It is established that a great variety of methods of liquid systems and solutions treatment are widely used in different brunches of food industry. The application of actual type of processing depends from many factors.

The research studies confirmed the possibility to amplification technological processes by innovative reagentless methods of physical influences. Every of these methods, modes and approaches has its own objective problems, which need the modern original solutions,

Chemical methods of treatment give the possibility for disinfection, inactivating pathogenic organisms and these methods can be used with large volumes of water and water solutions

Biological methods of water, water systems and wastewater solutions treatment are an important and essential part of any wastewater processing.

The physical and chemical properties and parameters of water, and liquid mediums, such as: oxidation-reduction potential, $\mathrm{pH}$ value, dissolved oxygen and etc. may be changed by the physical methods of energy influence.

Conclusions. The application of different methods of treatment in combination could improve the water treatment process environmentally. One of original and new procedure and equipment that was used for improvement of water treatment process is the method of discrete-pulsed input of energy. 


\section{Introduction}

At the present time one of the significant problems that are of attention to the scientific society is to extend original substandard goods and technologies that meet contemporary worldwide standards of quality and safety.

The availability of drinking water is limited, and it is shrinking worldwide. The world's 8.5 billion people will consume 6 trillion cubic meters $\left(6000 \mathrm{~km}^{3}\right)$ of water per year [1].

Water is an exceptional, omnipresent substance that is a major component of all living things, which has anomalous in many of its physical and chemical parameters and properties. Pure water and liquid water solutions and systems are used for fabricating, processing, washing and cleaning, diluting, cooling, or transporting products. Worldwide, agriculture and power generation are the main consumers of this raw material [2].

The purpose of this research is to investigate different methods of the treatment of the liquid systems and solutions for the change of the chemical and physical parameters and properties these liquid systems and solutions.

\section{Materials and methods}

\section{Materials}

Objects of research are different types of treatment and processing methods end modes of liquid water systems and solutions like as technological water for the application in food industry.

Subjects of study are the changing of the physical and chemical parameters and properties of liquid water systems and solutions which can form hydrogen bonds and associates of different variety.

Pure water and associated liquid aqueous systems and solutions were used for investigations and analyzing the change of their physical and chemical parameters and properties during the treatment and processing by the different methods and technological modes.

\section{Review methodology}

Scientific and research works, articles, proceedings of the conferences, thesis of the conferences, monographs of different methods, modes, processes of liquid systems treatment and equipment for processing were analyzed.

General scientific methods, such as analysis, comparison, and synthesis were used for research investigation. Literature referenced in this review was obtained from searches from bibliographic information in database and logic programming (DBLP), ISI Proceedings, Journal STORage (JSTOR) Search, Medline, Scopus, CAB abstracts, CABI full text, EBSCOhost, Google Scholar, PubMed, Web of Science, Emerging Sources Citation Index Web of Science Core Collection, SciFinder, Universal Impact Factor, ScienceDirect, Science Research Portal, Ingenta, SciNet - Science Search, CiteSeer Publications Researchindex etc. 


\section{Results and discussion}

Pure water and different liquid solutions and systems are plenty complicated associate systems, which are susceptible to the nominal quantity power influences.

In liquid solutions and pure water and in the aqueous solutions there is an unremitting threedimensional grating of hydrogen bonds; it proves to be true many researches by the numerical mathematical experiments and by mathematical modelling methods [3, 4].

Water, liquid solutions and systems has been modeled by different ways:

- As a uncomplicated continuous medium for fast calculations of solvatation or dielectric properties;

- As simplified statistical mechanical sphere-like particles with hydrogen bonding arms;

- by using fixed charge or polarizable atomically detailed models in computer simulations and modeling;

- At the computationally exclusive - quantum mechanical level for insights into the nature of electronic structure and the bonding of the atoms [5].

A number of our grandest large-scale challenges - distributing clean water, producing cheap and clean energy, providing greater food security, green ways to produce modern chemicals, and curing diseases - depend on a better understanding of water at the molecular level [6].

Inescapability of investigate of the structural formation of liquid aqueous solutions and systems and also liquid binary systems is rooted by their exceptional properties, and also special importance in lifeless and alive environment, a science and the techniques, contemporary technologies and production. Interactions with water are a major driving force for bimolecular structure and function in living systems.

Water, liquid solutions and systems can proceed as a solvent, product, reactant, catalyst, chaperone, messenger, and controller.

Water has distinctive liquid and solid properties in one time:

- It is highly cohesive;

- It has volumetric anomalies - water's solid (ice) floats on its liquid;

- Pressure can melt the solid rather than freezing the liquid;

- Heating can shrink the liquid;

- It has more solid phases than other materials [7].

The special directionality of the hydrogen bonds is responsible for many of the anomalous water properties. The hydrogen bond $\mathrm{H}$-bond is a strong bond which can formed between a polar hydrogen and another heavy atom, as a rule carbon, nitrogen, oxygen or sulfur in biological molecules [8,9].

There are many methods of water treatment for changing chemical and physical properties and parameters. In recent years researches and technologists and engineers have turned their interest to employment of the innovative non-traditional technologies and methods in processing of the liquid mediums, solutions, systems, which consists of the water or water solutions.

Nanotechnology embraces grand guarantee in ensuring safe drinking water through designing innovative centralized and decentralized household-level water treatment systems such as such as nanoadsorbents, photocatalysts, microbial disinfectants and in membranes [10].

An explanation process of water treatment include flocculation, sedimentation and media filtration to remove colloidal and suspended solids, ion exchanging, carbon adsorption and membrane processes to remove dissolved solids; and at last stage a disinfection for microbial inactivation that often performed by chlorination, ozonation and ultraviolet radiation [11]. 
The processes implicated in treating water and liquid aqueous systems and solutions rationale may be chemical, biological, physical and different combination between of them.

The quantity and type of treatment and processing depends on the source of water, liquid aqueous systems and solutions the function for which the water is required.

The preference of which type of treatment or processing to employ from a great variety of available processes depends on the characteristics of the water, the kind of the water quality problems to be current, and the costs of different methods of treatments.

Chemical methods of treatment give the possibility for disinfection, inactivating pathogenic organisms and these methods can be used with large volumes of water and water solutions, Figure 1. Such methods described above can reduce the number of pathogens in water, but do not always eliminate them completely.

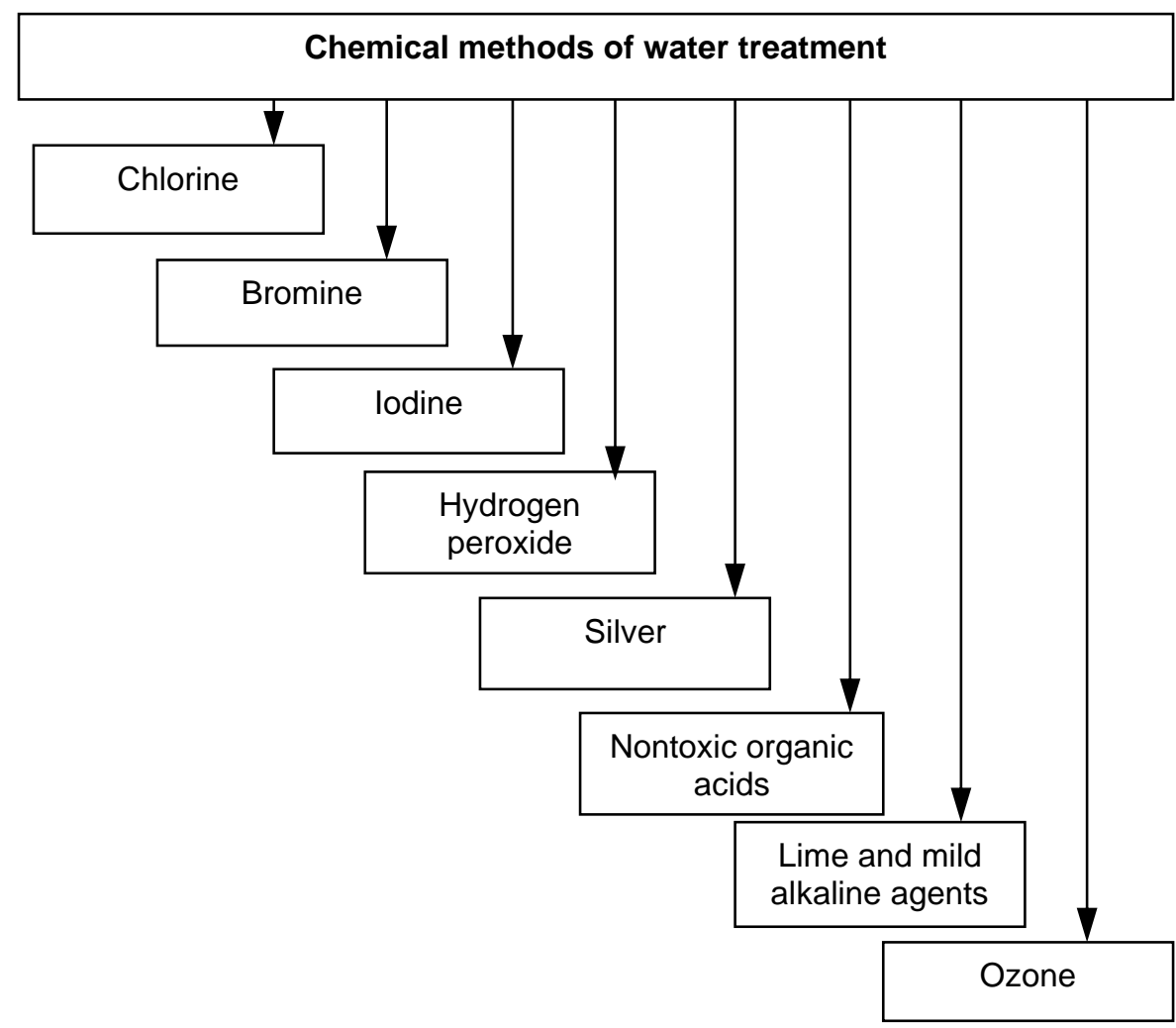

Figure 1. Some types of the chemical methods of water treatment

The main aim of the chemical methods of treatment water is to prevent pathogenic microorganisms causing the disease; to control unpleasant taste and appearance of particles; to remove the excessive color of water and turbidity; to extract the chemicals and dissolved minerals.

Chlorine is ordinary, inexpensive, but really toxic. Chlorine solutions lose strength while standing or when exposed to air or sunlight. 


\section{- Processes, Equipment and Control Systems -}

There are some types of chlorine used in water treatment. Some of them are:

- Chlorine gas;

- Calcium hypochlorite;

- Sodium hypochlorite;

Chlorine gas is greenish-yellow in color and heavier than air. Its high toxicity makes it an excellent disinfectant for water but also a danger to persons who handle it. Because of chemical changes that occur when it is introduced into water, chlorine gas is no more toxic to humans when used to treat drinking water than other forms of chlorine. Chlorine gas, which is really sold as an amber-colored compressed liquid, is the least expensive form of chlorine. Reactive chlorine species were main disinfectants at low current densities [12].

Calcium hypochlorite is manufactured from chlorine gas. It is best known as chlorine pellets and granules in water treatment. It is a white solid with a very pungent odor and it can create enough heat to explode. Calcium hypochlorite increases the $\mathrm{pH}$ of the water being treated [13].

Sodium hypochlorite is a chlorine-containing compound. It is a light yellow liquid that has a relatively short shelf life. It is the easiest to handle of all the types of chlorine. Sodium hypochlorite also increases the $\mathrm{pH}$ of the water being treated. A lower concentration of chlorine in this form is needed to treat water than with calcium hypochlorite or chlorine gas [14].

It does not decrease physical or chemical contamination. It does increase cholesterol formations, is a carcinogen, and causes heart infection. Besides disinfection of drinking water using chlorine can lead to the formation of genotoxic by-products when chlorine reacts with natural organic matter. Additionally, high dose chlorination of raw water induced genotoxicity [15].

The coagulant and chlorine consumption were also compared in the presence and absence of pre-sedimentation basin during non-flood condition. The results of investigations showed that in non-flood situation and using from pre-sedimentation tank didn't play significant role in decreasing the turbidity and coagulant consumption increased compared to none use of pre-sedimentation tank [16].

Bromine is used for water treatment, it is an oxidizing agent, and all form anions by accepting an electron, it has no smell and flavor as bad and doesn't kill microorganisms extremely well [17].

Bromine shows a very high reactivity toward phenolic groups, amines and sulfamides, and S-containing compounds, and high reactivity of bromine with inorganic compounds $\left(\mathrm{NH}_{3}, \mathrm{I}^{-}, \mathrm{SO}_{3}{ }^{2-}, \mathrm{NO}_{2}^{-}, \mathrm{CN}^{-}\right.$, etc) [18].

Model calculations show that depending on the bromide concentration and the $\mathrm{pH}$, the high reactivity of bromine may outweigh the reactions of chlorine during chlorination of bromide containing waters [19].

Iodine is not useful, toxic but used for water treatment. Iodine is ineffective for treatment of water infected with parasitic worm eggs and larvae and doesn't eliminate or neutralize farming and manufacturing chemicals, or heavy metals from water and water solutions. This halogen can act in response with assured contaminants causing residual chemicals or byproducts in drinking water after treatment is complete and its efficiency depends on the temperature, the lower the temperature the slower disperses iodine [20].

Hydrogen peroxide exterminates microorganisms with oxygen, is chemically through and is very toxic. This method used in emergencies. When hydrogen peroxide is put in to water a great quantity of dissolved oxygen is released and an influential oxidizing effect takes place [21]. 
Hydrogen peroxide oxidizes the iron, manganese and sulphur odours to a solid form that the catalytic carbon can remove. For a lot of appliances no contact reservoir is necessary, and the hydrogen peroxide is successfully indifferent by the catalytic carbon medium [22].

Silver is a valuable antiseptic but accumulative toxins which concentrates and doesn't evaporate.

Nontoxic organic acids should be applied with carefulness no supplementary than in large water plants.

Lime and mild alkaline agents should also be applied with carefulness just by big water plants, or only for laundry. Lime has more than a few recompenses, they are:

- To control of the potential of hydrogen;

- To neutralize of acidic waste water:

- To decrease in the concentration of oxidizing organic impurities;

- The clarification,

- The precipitation of dissolved impurities as well as flocculation and coagulation of colloidal particles.

There are two way of the using lime for water treatment. The first way is the using of quicklime and slaked lime. At the present time the second way is the most widely used lime product in water treatment is calcium hydroxide $\left(\mathrm{Ca}(\mathrm{OH})_{2}\right)$, with a purity of more than $90 \%$. The impact parameters which influence chemicals of emerging concern removal efficiencies of advanced water treatment technologies concern: chemicals of emerging concern characteristics; water matrix characteristics; treatment process conditions [23].

Neutralizing chemicals react with the unnecessary chemicals and produce outgases and sediment, but levels of need differ.

Coagulation-flocculation adds chemicals which lump together suspended particles for filtration or separation.

Ion exchange exchanges sodium from salt for calcium or magnesium, using either glauconite (greensand), precipitated artificial organic resins, or gel zeolite, thus softening the water. Minerals, metals, chemicals or odors are not affected, and the water is salty to drink.

Ozone can totally replace chlorine, chloramine or chlorine dioxide in the preoxidation and mainoxidation stages [24]. Ozone is an unstable gas comprising of three oxygen atoms, the gas will readily degrade back to oxygen, and during this transition a free oxygen atom, or free radical form.

The free oxygen radical is highly reactive and short lived, under normal conditions it will only survive for milliseconds. Ozone is effect over a wide $\mathrm{pH}$ range and rapidly reacts with bacteria, viruses, and protozoans and has stronger germicidal properties then chlorination.

Has a very strong oxidizing power with a short reaction time [25]. Ozone can eliminate a wide variety of inorganic, organic and microbiological problems and taste and odor problems.

Consequential from the enhanced microflocculation effect of ozone the filtration rates can be increased, smaller filtration beds used and even the chemical consumption lowered [26]. For the reason that of the higher oxidation potential of ozone it is also possible to reduce contact times, unless of course it becomes desirable to enhance the biological effect on granular activated carbon [27]. This method is very popular today.

Biological methods of water, water systems and wastewater solutions treatment are an important and essential part of any wastewater processing. Biological methods (Figure 2) of water treatment and processing are including: aerobic and anaerobic activated sludge processes, aerated lagoons, biofiltration. 


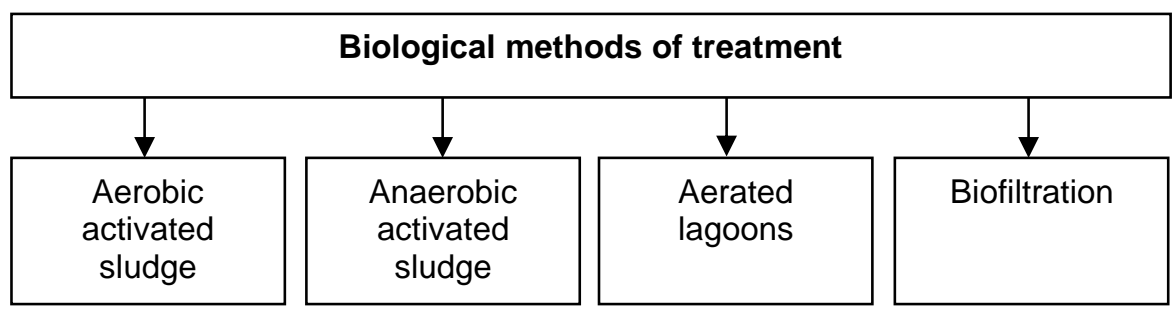

Figure 2. Some types of the Biological methods of water treatment

Biological treatment using aerobic activated sludge process has been in practice for well over a century. In general wastewater after primary treatment that is suspended impurities removal is treated in an activated sludge process based biological treatment system comprising aeration tank followed by secondary clarifier. The aeration tank is a completely mixed or a plug flow bioreactor where specific concentration of biomass is maintained along with sufficient dissolved oxygen concentration $2 \mathrm{mg} / \mathrm{l}$ to effect biodegradation of soluble organic impurities measured as biochemical oxygen demand or chemical oxygen demand [28].

Activated sludge systems, which are pure cultures and microbial mixed of the cultures, have been extensively studied, resulting in the deep understanding of the kinetics of the main and key heterotrophic and autotrophic biological processes, which sets the basis for the development of mechanistic models. A distinctive activated sludge wastewater treatment typically consists of a set of activated sludge tanks, sedimentation tanks; various recycle flows, and aeration systems of different types [29].

To model the biological wastewater treatment process, a high number of state variables and process descriptions, mostly based on Monod type kinetics, was used and combined in modeling structures [30].

Anaerobic activated sludge processes when the final products of organic assimilation in anaerobic treatment are methane and carbon dioxide gas and biomass.

Nowadays in wastewater treatment processes, physical and biochemical procedures are applied in order to decrease the organic matter levels, eliminate pathogenic organisms and improve water quality, so that water can be reused or released into the environment with minimal consequences.

Wastewater treatment processes carried out on aerated lagoons are widely used due to their relative low cost and maintenance requirements, minimum production of sludge and integration in the environment.

The system is based on the degradation and uptake of organic matter by a microbial community under toxic conditions [31].

A good understanding of the hydraulic performance of aerated lagoons is required for their design and operation. As a result a widespread numerical procedure has been developed for the three-dimensional computational modeling of the flow in large lagoons including high speed floating mechanical surface aerators [32].

At the present time biofiltration is widely used in drinking water treatment and in technological processes at plants as a supplement or enhancement of the conventional treatment [33]. Biofilters have dual utilities: the first is reducing the turbidity and pathogen particles like the conventional filters, and the other is removing the biodegradable organic matter and other bioavailable materials through the microbial metabolism of the biofilm attached to the media [34]. 
The second utility currently draws more attention because the micro-pollution of source water with biodegradable organic matter has become a common problem in many countries, especially in economically booming ones [35].

Biofiltration processes have developed over time, with careful filter media selection, nutrient and trace metal supplementation, oxidant amendment, and bioaugmentation of key microorganisms, to achieve improvements in water quality.

Biofiltration is on the precipice of a revolution that aims to customize the microbial community for targeted functional outcomes which might be to enhance or introduce target functional activity for contaminant removal, to keep away from hydraulic challenges, or to silhouette beneficially the downstream microbial community [36].

The physical and chemical properties and parameters of water, and liquid mediums, such as: oxidation-reduction potential, $\mathrm{pH}$ value, dissolved oxygen and etc. may be changed by the physical methods of energy influence.

Non-reagent methods and modes of water processing and liquid water binary systems treatment are shown on Figure 3.

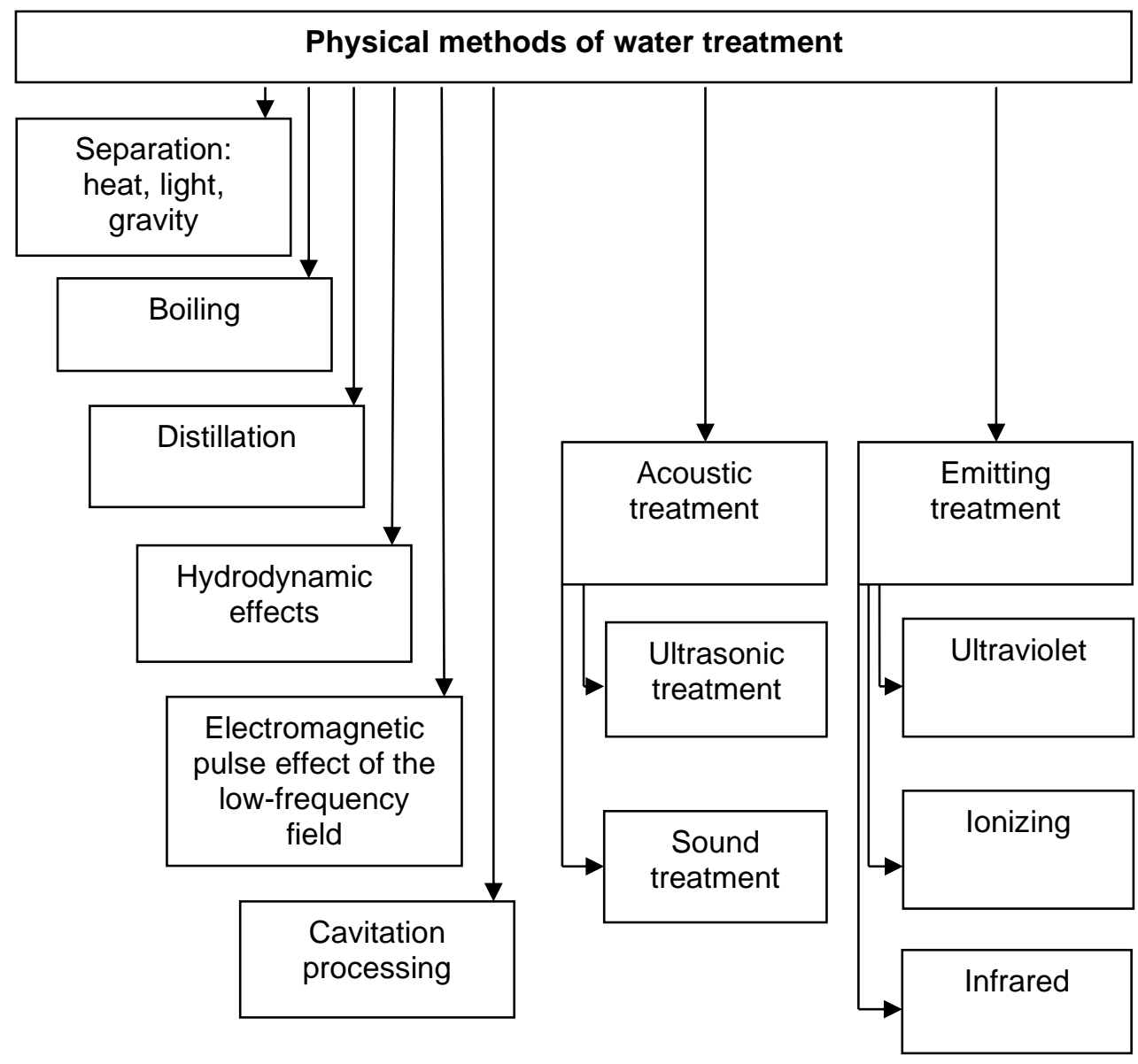

Figure 3. Some types of the physical methods of water treatment 
They include: separation: heat, light, gravity; boiling; distillation; hydrodynamic effects; the electromagnetic pulse effect of the low-frequency field; cavitation processing; acoustic treatment: ultrasonic treatment, sound treatment; emitting treatment: ultraviolet, ionizing, infrared.

Separation: heat, light, gravity gravitationally settles heavy suspended material. Removes suspended particles from water to improve its appearance. As a result of such treatment, water turbidity and color index are reduced.

The effectiveness of sedimentation may however, be increased by mixing certain chemicals with water, to form flocculent precipitates, which carries the suspended particles as it settles The finer particles in suspension, which may avoid settling in sedimentation basins even after using the chemical coagulation, may then be removed by filtering the water through filters [37].

Boiling kills $99.9 \%$ of all living things and vaporizes most chemicals. Minerals, metals, solids and the contamination from the cooking container become more concentrated [38].

Distillation boils and recompenses the water, but many chemicals vaporize and reconvene in concentration in the output water.

Boiling and distillation are very expensive and with high energy consumption methods of water treatment.

A great number of alternative methods are commercially available for the elimination of microbiological pollutants and several chemical contaminants from water sources.

Hydrodynamic effects occur at water and water binary systems and different water mixtures and solutions treatment by physical and mechanical methods or so-called non reagent (reagentless).

The method of discrete-pulsed input of energy (DPIE) is one of physical methods of treatment with many hydrodynamic effects, such as power of pressure of shift, cavitations, the effect of explosive boiling, collective effects in assembly of vials, crossness of an interphase surface in gas-liquid bubbly medium, action of hydrodynamic oscillations, alternating impulses of pressure, effects which associated with acceleration of movement of a continuous phase.

The major effects of the discrete-pulsed input of energy are related with increase of velocity of association of a continuous phase of medium.

The method of DPIE can influence on structural and energy transformation in multifarious liquid mediums on micro- and nano- level and gives opportunity to begin physical and chemical alteration in these mediums [39].

The fundamental nature of a DPIE method consists in that preliminary permanently entered and any rank the energy distributed in working volume to accumulate in locally disconnected discrete points of system and further pulse to realise for achievement of necessary physical effects: forcing and dumping of pressure, adiabatic boiling, hydraulic blow, shock waves of pressure or depression, pressure of shift, local turbulence, cavitation and many other effects [40].

Three-dimensional and period concentration of energy gives the possibility to receive the big capacity of pulsation power accomplishment, to release internal energy of substance, to create active energetic processes which take place at microlevel and also at nanolevel.

The development of different microliquid devices for some last decades has caused growth of interest to microscale streams. Rotary pulse apparatus are characterised by small enough sizes of width of channels which gives the chance to consider them as microchannels with effects of slippage a stream on walls. 
A number of heat and mass technological processes (structuring, crushing, dispersion, emulsification, homogenization, mixing, etc.) are spend in rotary pulse apparatus of cylindrical type which realise principles of discrete-pulsed input of energy.

Investigating of new methods, apparatus and industrial technologies are concentrating on raise of an overall presentation of procedure and an increase of processes in environments which involves complex researches on learning of hydrodynamic conditions, modelling of processes in new devices.

In recent times there has been considerable investigation of the electromagnetic pulse effect of the low-frequency field on water or on the behaviour of aqueous solutions. The physical and chemical properties and parameters of water, such as: oxidation-reduction potential, potential of hydrogen, dissolved oxygen and atc. may be tainted by the magnetic and electromagnetic fields. These changes depend from the field intensity and frequency. Even though intensive research, the mechanisms by which electromagnetic fields act on water are still a controversial issue [41]. Extremely low frequency electromagnetic fields have significant and lasting effects on liquid water [42].

The majority of theories explain effect of magnetic processing of water magnetic field achievement on there is at water ions of salts which are exposed to polarisation and deformation [43]. As main and explanation parameters of devices for processing of water by a magnetic field intensity of a magnetic field, time of stay of water provide in an active zone or sector of a magnetic field, frequency velocity and periodicity of power influence of a field on water, speed of a stream of water in the device [44].

Today the cavitation processing is one of the innovate technologies that was used for improvement of water treatment process. By definition cavitation consists in formation of ruptures of sites of liquid small vials, under the influence of the intelligent changes of pressure caused by movement of a liquid.

The cavitation is the experience of the formation, growth and collapse of microbubbles or cavities occurring in extremely small interval of time milliseconds in a liquid [45].

The cavitation can be used as the working instrument for the organisation of different technological processes, for example for: clarifications and processing's of surfaces, hashing of multiphase streams: a liquid - a liquid, gas - a liquid, firm particles - a liquid etc., activation of chemical reactions, structuring and is finishing, in technologies of clarification and water disinfecting. In the conditions of cavitation hydroxyl $\left(\mathrm{OH}^{-}\right)$and hydrogen $\left(\mathrm{H}^{+}\right)$radicals would be formed by thermal dissociation of water and oxygen [46].

At the present time the numerous applications of acoustic treatment: ultrasonic treatment and sound treatment, the advance is employed in the field of water treatment.

Among available technologies, ultrasound technology has a significant potential to produce good-quality, healthful, delicious, and affordable convenience food products and different drinks [47]. The numerous applications of ultrasound, the come within reach of are used in the field of water treatment for different brunches of industries and productions.

Ultrasonic treatment in a liquid leads to the acoustic cavitation phenomenon such as formation, growth, and collapse of bubbles - cavitation, accompanied by generation of local high temperature, pressure, and reactive radical species $(\mathrm{OH}, \mathrm{OOH})$ with thermal dissociation of water and oxygen [48].

Nowadays emitting treatment is very perspective method of the processing. There are many modes and different combinations of the emitting treatment for the water solutions processing for foodstuff production. This method includes: ultraviolet, ionizing, infrared emitting. 


\section{- Processes, Equipment and Control Systems -}

Conventionally, the ultraviolet spectrum is divided into three discrete sections: Ultraviolet A, with wavelength $320-400 \mathrm{~nm}$; Ultraviolet B, with wavelength $280-320 \mathrm{~nm}$; Ultraviolet C, with wavelength less than $280 \mathrm{~nm}$ [49].

Revelation to ultraviolet light can consequence in the construction of a range of photoproducts whose distribution and comparative yields depend on the wavelength and intensity of occurrence emission.

Infrared mode of treatment of water and water solutions used for micro-organism inactivation, disinfection also for structural transformation by the infrared radiation and emission.

But infrared laser water treatment apparatus is limited, on the other hand, by the energy consumption and expenditure required activating water properties and parameters [50].

The photocatalysis has immense potential as an unconventional or alternative water treatment and processing method outstanding to possibility to remove by-product precursors [51]. This process also ensures the public health safety of drinking water due to its ability to inactivate micro-organisms and to change physical and chemical parameters of water.

The photocatalytic procedures are divided into two processes: homogeneous photocatalytic oxidation, for example ultraviolet or hydrogen peroxide and heterogeneous photocatalytic oxidation, such as ultraviolet or semiconductor photocatalysis [52].

Further investigation is needed to better understanding of the change physical and chemical parameters of water systems and technological water solutions during treatment. It will give the possibilities to create and design new energy and power saving technologies, modes, equipment and apparatus of water treatment for foodstuff production.

\section{Conclusions}

As a result of research, it was found that the application of different methods of treatment in combination could improve the water treatment process more environmentally.

Every of these methods, modes and approaches has its own objective and intention problems and its own research area.

At the present time one of original and new procedure and equipment that was used for improvement of water treatment process is the method of discrete-pulsed input of energy.

There are many various parameters that can affect to application and efficiency of in discrete-pulsed input of energy on water treatment such as: power, frequency, velocities, constructive design of the working chamber and clearances, time of processing.

Experimental and theoretical studies have shown that the method of discrete-pulsed input of energy may be suitable for processing in food industry, where hydrodynamic effects are found to be an alternative to traditional methods of technological water and water solutions treatment.

The various parameters and effects could influence to the efficiency of the processing and can greatly reduce the duration of the process, reduce power and raw material consumption, increase capacity.

\section{References}

1. Water Resources Group (2016), Charting Our Water Future: Economic Frameworks to Inform Decision-Making, Available at: http://www.2030wrg.org/wp-content/uploads /2014/07/Charting-Our-Water-Future-Final.pdf (accessed September 15, 2016). 
2. Singh V.P., Shalini Yadav, Ram Narayan Yadava (2018) Water quality management: select proceedings of ICWEES-2016, Water science and technology library, 79 Singapore, Springer.

3. Mijaković M. Kežić B., Zoranić L., Sokolić F., Asenbaum A., Pruner C., Emmerich Wilhelm, Perera A. (2011), Ethanol-water mixtures: ultrasonics, Brillouin scattering and molecular dynamics, Journal of Molecular Liquids, 164(1-2), pp. 66-73.

4. Marcin Rybicki, Ewa Hawlicka (2014), Influence of ions on molecular vibrations and hydrogen bonds in methanol-water mixtures: MD simulation study, Journal of Molecular Liquids, 196, pp. 300-307.

5. Lukšič M., Fennell C. J., Dill K. A. (2014), Using Interpolation for Fast and Accurate Calculation of Ion-Ion Interactions. J. Phys. Chem., 118, pp. 8017-8025

6. Emiliano Brini, Christopher J. Fennell, Marivi Fernandez-Serra, Barbara Hribar-Lee, Miha Lukšič, Ken A. Dill (2017), How Water's Properties Are Encoded in Its Molecular Structure and Energies Chem Rev. 117(19), pp. 12385-12414.

7. Wagner W., Prub A. (2002), The IAPWS Formulation 1995 for the Thermodynamic Properties of Ordinary Water Substance for General and Scientific Use. J. Phys. Chem. Ref. Data, 31, pp. 387-535

8. Sun C. Q. Sun Y. Castleman A. W., Toennies J. P., Yamanouchi K., Zinth W., Eds. (2016), In Springer Series in Chemical Physics, 113, Springer, Singapore.

9. Ben-Naim A. (2011), Molecular Theory of Water and Aqueous Solutions: Part II: The Role of Water in Protein Folding, Self- Assembly and Molecular Recognition, World Scientific, Singapore.

10. Prathna T.C. Saroj Kumar Sharma, Maria Kennedy (2018), Nanoparticles in household level water treatment: An overview Separation and Purification Technology, 199, pp. 260 270

11. Tansel B. (2008), New technologies for water and wastewater treatment: A survey of recent patents. Recent Patents on Chemical Engineering, 1, pp. 17-26

12. Saloumeh Ghasemian, Bahareh Asadishad, Sasha Omanovic, Nathalie Tufenkji (2017), Electrochemical disinfection of bacteria-laden water using antimony-doped tin-tungstenoxide electrodes, Water research, 126, pp. 299-307

13. Brian Oram, P.G. (2014) Chlorination of Drinking Water - Private Well Owner Guide Private Well Owner Guide and Small Water, by Environmental Consultants Inc. 8 p.

14. (2018), Types of Chlorine Used in Water Treatment, Pure Water Products, LLC.

15. Johan Lundqvist, Anna Andersson, Anders Johannisson, Elin Lavonen, Geeta Mandava (2019), Innovative drinking water treatment techniques reduce the disinfection-induced oxidative stress and genotoxic activity, Water Research, 5, pp. 182-192

16. Taghizadeh, Mohammad Mehdi (2018), Pre-sedimentation tank effects on water treatment unit operation, International Journal of Environmental Quality, 28, pp. 35-42

17. Joseph Cotruvo (2015), Contaminant of the month: bromine and bromine disinfection, EPA Drinking Water Standards Division.

18. Michèle B. Heeb, Justine Criquet, Saskia G. Zimmermann-Steffens, Urs von Gunten (2014), Oxidative treatment of bromide-containing waters: Formation of bromine and its reactions with inorganic and organic compounds - A critical review, Water Research, 48, pp. $15-42$

19. Michèle B. Heeb, Justine Criquet, Saskia G. Zimmermann-Steffens, Urs von Gunten (2014), Oxidative treatment of bromide-containing waters: Formation ofbromine and its reactions with inorganic and organic compounds - A critical review, Water Research, 48, pp. $15-42$

20. Zimmermann M. B., Anderson M. (2011), Prevalence of iodine deficiency in Europe in 2010, Ann d'endocrinol, 72, pp. 164-166 
21. Luo, Y., Guo, W., Ngo, H.H., Nghiem, L.D., Hai, F.I., Zhang, J., Liang, S, Wang X.C. (2014), A review on the occurrence of micropollutants in the aquatic environment and their fate and removal during wastewater treatment. Sci. Total Environ., pp. 473-474 and pp. 619-641

22. Hofman-Caris, R.C.H.M., Harmsen, D.J.H., Puijker, L., Baken, K.A., Wols, B.A., Beerendonk, E.F., Keltjens, L.L.M. (2015), Influence of process conditions and water quality on the formation of mutagenic byproducts in $\mathrm{UV} / \mathrm{H}_{2} \mathrm{O}_{2}$ processes, Water Res., 74, pp. 191-202

23. Astrid Fischer, Annemarie P. van Wezel, Juliane Hollender, Emile Cornelissen, Roberta Hofman, Jan Peter van der Hoek (2019), Development and application of relevance and reliability criteria for water treatment removal efficiencies of chemicals of emerging concern, Water Research, 161, pp. 274-287

24. van Wezel, A.P., ter Laak, T.L., Fischer, A., Bauerlein, P.S., Munthe, J., Posthuma, L. (2017), Mitigation options for chemicals of emerging concern in surface waters, operationalising solutions-focused risk assessment, Environ. Sci.: Water Res. Technol. 3 (3), pp. 403-414

25. Ternes T.A., Stüber J., Herrmann N., McDowell D., Ried A., Kampmann M., Teiser B. (2003), Ozonation: a tool for removal of pharmaceuticals, contrast media and musk fragrances from wastewater, Water Res., 37(8), pp. 1976-1982.

26. Montiel A. et al. (1984), Influence du coagulant lors de l'élimination des micropolluants minéraux par les traitements de clarification. Journal Français d'Hydrologie, 15 (2), pp. 119-129

27. Richard Y., Duguet J.-P. and Hubele C. (1991), Pesticides et eau potable. L'Eau, l'Industrie, les Nuisances, 144, pp. 44-46.

28. Arun Mittal (2011), Biological Wastewater Treatment, Water Today, l August, pp. 32-44

29. K.V. Gernaey, G. Sin (2013), Wastewater Treatment Models, in Reference Module in Earth Systems and Environmental Sciences, pp. 1-5

30. Cláudia F. Galinha, S Sanches, João G. Crespo (2018), Membrane bioreactors, Fundamental Modelling of Membrane Systems, pp. 209-249

31. Alexandra Moura, Marta Tacao, Isabel Henriques, Joana Dias, Pedro Ferreira, Antonio Correia (2009), Characterization of bacterial diversity in two aerated lagoons of a wastewater treatment plant using PCR-DGGE analysis, Microbiological Research, 164, pp. 560-569

32. Konstantin Pougatch, Martha Salcudean, Ian Gartshore, Philip Pagoria (2007), Computational modelling of large aerated lagoon hydraulics, Water Research, 41(10), pp. 2109-2116

33. Urfer, D., Huck, P. M., Booth, S. D. J., and Coffey, B. M. (1997), Biological filtration for BOM and particle removal: a critical review. Journal of the American Water Works Association, 89(12), pp. 83-98.

34. Yu Xin, Ye Lin, Wei Gu (2008), Modeling the formation of soluble microbial products (SMP) in drinking water biofiltration, Water Science and Engineering, 1(3), pp. 93-101.

35. Wang Z. S., and Liu W. J. (1999), Drinking Water Treatment with Micro-polluted Source Water, Beijing: China Architecture and Building Press (in Chinese).

36. Mary Jo Kirisits, Monica B. Emelko, Ameet J. Pinto (2019), Applying biotechnology for drinking water biofiltration: advancing science and practice, Current Opinion in Biotechnology, 57, pp. 197-204

37. Haseeb Jamal (2017), Purpose and Methods of Treatment of Waste Water, Urban Waste Management, pp. 10-15

38. Cicek V. (2013), Corrosion and corrosion prevention in boilers, Cathodic protection: industrial solutions for protecting against corrosion, Hoboken, New Jersey, John Wiley \& Son. 
39. Dolinskij A.A., Basok B.I. (2005), Nanoscale effects by discrete-pulsed transformation of energy, IFZH, 78(1), pp. 15-23

40. Dubovkina Iryna (2017), Change of physical and chemical parameters of the liquid binary systems by alternating impulses of pressure, Ukrainian Food Journal, 6(1), pp. 142-154.

41. Yamashita M, Duffield C, Tiller W.A. (2003), Langmuir, 19, pp. 6851-6856.

42. Laughrey Z., Bear E., Jones R., Tarr M.A. (2001), Aqueous sonolytic decomposition of polycyclic aromatic hydrocarbons in the presence of additional dissolved species, Ultrason Sonochem, 8, pp. 353-357.

43. Philippe Vallee, Jacques Lafait, Laurent Legrand, Pascale Mentre, Marie-Odile.Monod, Yolene Thomas (2005), Effects of pulsed low frequency electromagnetic fields on water characterized by light scattering techniques: role of bubbles, Langmuir, pp. 1-17

44. Oshitani, J., Uehara, R., Higashitani, K. (1999) Low frequency electromagnetic fields $J$. Colloid Interface Sci., 209, pp. 374-379

45. Chua S.Y., Adul Latif P., Ibrahim Sh., et al. (2010), Effect of ultrasonic irradiation on COD and TSS in raw rubber mill effluent, Environment Asia, 3(special issue), pp. 32-35

46. Jiang Y., Petrier C.H., Waite T.D. (2002), Effect of $\mathrm{pH}$ on the ultrasonic degradation of ionic aromatic compounds in aqueos solution, Ultrason Sonochem, 9, pp. 163-168

47. Doosti M.R., Kargar R., Sayadi M.H. (2012), Water treatment using ultrasonic assistance: A review, Proceedings of the International Academy of Ecology and Environmental Sciences, 2(2), pp. 96-110

48. Mahvi A.H. (2009), Application of ultrasonic technology for water and wastewater treatment, Iranian J Publ Health, 38(2), pp. 1-17

49. Joao Gomesa, Eva Dominguesa, Marta Gmureka, Rosa M. Quinta-Ferreiraa, Rui C. Martinsa (2019), Advanced oxidation processes for recalcitrant compounds removalcomparison with biofiltration by Corbicula fluminea, 6th International Conference on Energy and Environment Research, ICEER 2019, 22-25 July, University of Aveiro, Portugal, p. 6

50. Ahmed M, Zhou J, Ngo H, Guo W, Thomaidis N, Xu J. (2017), Progress in the biological and chemical treatment technologies for emerging contaminants removal from wastewater: A critical review, J. Hazard Mat, 323, pp. 274-298

51. Yu Qiu, Er Bei, Shuguang Xie, Shixiang Li, Jun Wang, Xiaojian Zhang, Stuart Krasner, Chao Chen (2019), Contributions of volatilization, photolysis, and biodegradation to $\mathrm{N}$-nitrosodimethylamine removal in conventional drinking water treatment plants, Science of The Total Environment, 697, 133993

52. Sarah Ede (2006), Infrared and photocatalytic studies of model bacterial species for water treatment, Inorganic Materials Research Program Sch. of Phys. and Chem. Sciences Queensland Univ. of Technology, pp. 9-11 